\title{
A longitudinal analysis of fatigue in colorectal cancer patients during chemotherapy
}

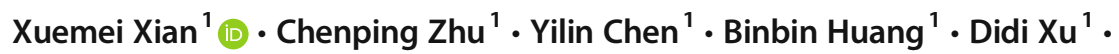

Received: 21 October 2020 / Accepted: 19 February 2021 / Published online: 1 March 2021

(C) The Author(s) 2021

\begin{abstract}
Purpose The aim of this longitudinal study was to analyze trends in fatigue among colorectal cancer patients during chemotherapy and examine the predictors of multidimensional fatigue.

Methods A mixed sample of colorectal cancer patients who were receiving chemotherapy $(N=200)$ was recruited in China. The patients completed the Cancer Fatigue Scale (CFS) at baseline (before chemotherapy) and after 3 and 6 months of chemotherapy. Repeated measures ANOVAs were conducted to evaluate the effect of time on the CFS score. The data on violations of the statistical assumptions (independence, normality, and sphericity) from the repeated measures ANOVAs were examined. Stepwise regression analyses were conducted to evaluate the associations of the potential predictor variables at baseline on the total fatigue score and subscale scores at follow-up.

Results As chemotherapy progressed, significant increases in the three subscale scores and total scores were observed. Physical fatigue and total fatigue scores increased continuously during chemotherapy $(P<0.001)$. However, affective fatigue and cognitive fatigue scores increased significantly in the first 3 months $(P<0.001)$ and basically remained stable thereafter $(P>$ $0.05)$. Multiple stepwise regression was used to analyze the predictors. The results showed that the baseline fatigue subscale score was the strongest predictor of each dimension of fatigue. In addition, age affected physical fatigue, and monthly income and education affected cognitive fatigue.

Conclusion Fatigue increased during chemotherapy. Early assessment and intervention may be better for controlling fatigue, especially in patients with higher baseline fatigue level, older age, and lower economic and educational levels.
\end{abstract}

Keywords Colorectal cancer $\cdot$ Fatigue $\cdot$ Chemotherapy $\cdot$ Longitudinal design $\cdot$ CFS

\section{Introduction}

Cancer-related fatigue is a common symptom in patients with colorectal cancer, especially in those receiving chemotherapy, with an incidence of up to $80 \%$ [1], and approximately $30 \%$ of patients experience persistent or chronic fatigue $[2,3]$. The National Comprehensive Cancer Network defined cancerrelated fatigue (CRF) as a "distressing persistent, subjective sense of physical, affective and/or cognitive tiredness or exhaustion related to cancer or cancer treatment that is not

Xuemei Xian

xianxuemei@zju.edu.cn

$1 \quad$ Sir Run Run Shaw Hospital, School of Medicine, Zhejiang University, No. 3 East Qingchun Road, Hangzhou 310016, China proportional to recent activity and interferes with usual functioning" [1]. CRF is a multidimensional symptom that includes three dimensions: physical fatigue, affective fatigue, and cognitive fatigue $[1,4]$.

Studies have shown that the pathogenesis of CRF may include physiological/biochemical, psychological, social, and other factors $[3,5-7]$, but the results are not completely consistent. Therefore, the management of CRF presents significant challenges for health professionals.

Fatigue has a profound effect on quality of life, for example, reducing patients' energy levels, causing changes in daily life, and exacerbating other symptoms [8]. It may even reduce patients' ability to engage in valuable life activities and socialize. Studies have shown that CRF affects patients longer and more severely than most other symptoms [9]. Greater knowledge of the factors that predict fatigue will help care providers better identify patients at risk for fatigue during treatment and help them develop the most effective individualized 
intervention plans. In addition, the adverse effects of fatigue on quality of life $[8,10]$, work capacity $[11,12]$, and compliance can be reduced through the provision of early intervention programs [13].

Previous longitudinal studies have revealed that patients who experience fatigue at the beginning of treatment are more likely to suffer from fatigue during chemotherapy [14, 15]. The other major predictive factors reported in the literature include depression $[6,15]$, age $[11,16]$, female sex [11], chemotherapy [11], occupational status [14], and physical limitations. However, most relevant studies have used the total fatigue score as a predictor and have not accounted for multidimensional fatigue. By definition, fatigue is multidimensional, affecting the body, emotion, and cognition, and there may be different factors influencing the characteristics of different dimensions of fatigue. Therefore, we consider it necessary to identify specific predictors of the physical, emotional, and cognitive dimensions of fatigue.

The purpose of this longitudinal study was to analyze trends in fatigue among colorectal cancer patients during chemotherapy and examine the predictors of multiple dimensions of fatigue. We estimated the predictive factors for severe fatigue based on the relationships between different baseline variables and fatigue over a 6-month chemotherapy period, but we did not identify the causes of fatigue. Referring to the multifactorial concept of the perpetuation of CRF, we tested the impact of sociodemographic, clinical, and baseline levels of fatigue on the total fatigue score and subscale scores.

\section{Methods}

\section{Study design}

A longitudinal study was conducted to assess the prevalence of fatigue among colorectal cancer patients before chemotherapy and after 3 and 6 months of chemotherapy and to examine the associations of the predictors with fatigue over a 6-month period.

\section{Patients and settings}

The study took place between October 2017 and April 2018 at a teaching hospital in China. A group of 200 patients with colorectal cancer were recruited through convenience sampling. Patients were eligible if they (1) were more than 18 years old and had colorectal cancer, (2) had accepted postoperative chemotherapy, and (3) had agreed to participate in this study, had signed the informed consent form, had the ability to understand and write Chinese, and could communicate effectively with the researchers.

The exclusion criteria were as follows: patients who (1) had known psychiatric diseases or dementia, (2) had a history of malignancy or chemotherapy, (3) had received radiation concurrent with chemotherapy, (4) had immune disorders or were using immunosuppressive medication upon enrollment in the study, (5) had severe chronic metabolic diseases or nutritional disorders, and (6) had an estimated life expectancy of 6 months or less.

\section{Instruments}

\section{General information questionnaire}

Demographic information and information on disease/ treatment factors were collected from the patients' medical records and via a study-specific patient information questionnaire that included items on age, sex, education level, income, employment status, marital status, type of chemotherapy (FOLFOX6 or XELOX), stage of the disease at diagnosis, and presence of colostomy.

\section{Cancer Fatigue Scale}

The Cancer Fatigue Scale was developed by Okuyama et al. [17]. This scale includes three subscales: physical fatigue, affective fatigue, and cognitive fatigue. There are a total of fifteen items on the scale. All items are scored on a 5-point Likert scale from 1 ("not at all") to 5 ("extremely"). The physical subscale included 7 items ("easily tired," "having urge to lie down," "exhausted," "heavy and tired," "reluctant," "fedup," and "don't know what to do with yourself"). The affective subscale included 4 items ("energetic feeling," "interest in something," "encourage yourself to do something," and "ability to concentrate"). The cognitive subscale included 4 items ("forgetful," "errors while speaking," "thinking has become slower," and "careless"). Higher scores indicate a higher degree of fatigue. The test-retest reliability is 0.88 , and the validity is good. In 2011, the CFS was translated into Chinese by Feng-ling Zhang et al. [18]. The Cronbach's alpha of the Chinese version of the questionnaire is 0.86 . We obtained permission to use the CFS-C from Zhang.

\section{Study procedures}

This study was approved by the ethics committee of the Sir Run Run Shaw Hospital. Before chemotherapy, a clinical staff member explained the study to the patient and determined his/ her willingness to participate. The research nurse met with the patients; determined their eligibility; provided them with written information on the study protocol, purpose, risks, and benefits and addressed their concerns; and obtained their written informed consent. Participation was completely voluntary for all patients. In general, chemotherapy for colorectal cancer usually occurs once per month for a total of 6 months. Therefore, after providing consent, the patients completed 
the questionnaires before chemotherapy and after 3 months (mid-chemotherapy) and 6 months (post-chemotherapy). All questionnaires were distributed and collected by two research nurses and completed by the patients anonymously with no interference. The research nurses met with the patients at the Clinical Research Center when they returned to the hospital for chemotherapy. To increase the accuracy of the questionnaires, the participants were given $15 \mathrm{~min}$ to complete them. All medical data were obtained from (electronic) patient records.

\section{Data analyses}

All analyses were performed using IBM SPSS 21.0, with the statistical significance set at $P<.05$. Descriptive statistics are presented as the mean $\pm \mathrm{SD}$ for numerical variables and $n(\%)$ for categorical variables. An independent sample $t$-test was performed to compare the differences in the continuous variables between the two groups when normality and homogeneity assumptions were satisfied; repeated measures ANOVAs were conducted to evaluate the effect of time on the CFS score. The data on violations of the statistical assumptions (independence, normality, and sphericity) from the repeated measures ANOVAs were examined. Stepwise regression analyses were conducted to evaluate the associations of the potential predictor variables at baseline with fatigue at follow-up.

\section{Results}

\section{Sample characteristics}

A total of 200 patients were eligible, agreed to participate in the study, and provided data, and 174 (87\%) of these patients returned the questionnaire at all three measurement points. The demographic data for all the patients in the study are presented in Table 1. Among the 174 patients, 98 were male, and 76 were female. The mean age of all the patients was 60.53 years (SD 10.53). The majority of the patients had at least a middle school education $(n=154,88.51 \%)$, were not working ( $n=106,60.92 \%)$, and had a monthly household income greater than $10,000 ¥(n=82,47.3 \%)$. A total of 118 $(67.82 \%)$ of the patients had stage III colorectal cancer and 34 (19.54\%) had stage IV colorectal cancer. Among the patients with stage IV disease, 31 patients had liver metastases and 3 had lung metastases. Twenty-one patients with liver metastases underwent the resection of liver metastases concurrent with the primary resection, and 9 patients underwent radiofrequency ablation at the time of surgery. Two patients with lung metastases underwent radiofrequency ablation and then resection for the primary colorectal cancer. The other two patients only underwent the primary resection and did not receive
Table 1 Patient characteristics $(n=174)$

\begin{tabular}{|c|c|}
\hline Variables & $n(\%)$ \\
\hline \multicolumn{2}{|l|}{ Demographic characteristics } \\
\hline \multicolumn{2}{|l|}{ Age } \\
\hline Mean (SD) & $60.53(10.53)$ \\
\hline Range & $41-76$ \\
\hline \multicolumn{2}{|l|}{ Sex } \\
\hline Male & $98(56.32)$ \\
\hline Female & $76(43.68)$ \\
\hline \multicolumn{2}{|l|}{ Education } \\
\hline Primary school & $20(11.49)$ \\
\hline Middle school & 139(79.89) \\
\hline University & $15(8.62)$ \\
\hline \multicolumn{2}{|l|}{ Marital status } \\
\hline Married & $145(83.33)$ \\
\hline Divorced/separated/widowed & $29(16.67)$ \\
\hline \multicolumn{2}{|l|}{ Employment status } \\
\hline Working & $68(39.08)$ \\
\hline Not working & 106(60.92) \\
\hline \multicolumn{2}{|l|}{ Monthly household income } \\
\hline$<5000 ¥$ & $33(18.97)$ \\
\hline $5000-10,000 ¥$ & $59(33.91)$ \\
\hline$>10,000 ¥$ & $82(47.13)$ \\
\hline \multicolumn{2}{|l|}{ Medical characteristics } \\
\hline \multicolumn{2}{|l|}{ Diagnosis } \\
\hline Colon cancer & $87(50)$ \\
\hline Rectal cancer & $87(50)$ \\
\hline \multicolumn{2}{|l|}{ Overall stage of disease } \\
\hline Stage II & $22(12.60)$ \\
\hline Stage III & $118(67.82)$ \\
\hline Stage IV & $34(19.54)$ \\
\hline \multicolumn{2}{|l|}{ Colostomy } \\
\hline Yes & $67(38.51)$ \\
\hline No & $107(61.49)$ \\
\hline \multicolumn{2}{|l|}{ Type of chemotherapy } \\
\hline FOLFOX & $90(51.72)$ \\
\hline XELOX & $84(48.28)$ \\
\hline
\end{tabular}

Abbreviations: $S D$ standard deviation

treatment for the metastases. In total, $61.49 \%$ of the patients did not have a colostomy, and $51.72 \%$ received FOLFOX chemotherapy. The most common adverse reaction during chemotherapy was nausea and vomiting, with $27.58 \%$ of patients suffering from mild-to-moderate nausea and vomiting. A 5-HT3 receptor antagonist was used to prevent nausea and vomiting. Another common adverse event was myelosuppression, which occurred in $13.21 \%$ of the patients. Colony stimulating factor was used to treat myelosuppression. All patients completed 6 cycles of chemotherapy as planned. At the end of chemotherapy, 169 patients had no tumor 
recurrence, while 3 patients had new liver metastases. The 2 stage IV patients who did not receive treatment for their metastases achieved a partial response.

\section{Prevalence of fatigue}

Table 2 shows that the mean fatigue scores were 18.5 (physical fatigue), 10.85 (emotional fatigue), and 10.58 (cognitive fatigue) at baseline. The corresponding follow-up values were $20.32,12.02$, and 11.07 at 3 months and 23.16, 12.01, and 11.25 at 6 months, respectively. As chemotherapy progressed, statistically significant increases in fatigue severity were observed in all three subscale scores and the total score $(P<$ 0.01), which are shown in Fig. 1(a-d).

\section{Longitudinal differences in fatigue}

The repeated measures ANOVAs showed statistically significant differences in all three subscale scores and the total score (Table 3). The physical fatigue score significantly increased between t_baseline and t $3 \mathrm{~m}$ (from 18.05 to 20.32 points; $p<$ 0.001 ) as well as between $\mathrm{t} 3 \mathrm{~m}$ and $\mathrm{t} \_\mathrm{m}$ (from 20.32 to 23.16 points; $p<0.001)$. On the other hand, the affective fatigue and cognitive fatigue scores increased significantly between t_baseline and t $3 \mathrm{~m}$ (from 10.85 to $12.02, p<$ 0.001 and from 10.58 to $11.07, p<0.001$, respectively) and basically remained stable between $\mathrm{t} \_3 \mathrm{~m}$ and t $6 \mathrm{~m}$ (from 12.02 to $12.01, p=0.931$, and from 11.07 to $11.25, p=$ 0.406 , respectively). Finally, the total fatigue score increased continuously during chemotherapy, from 39.48 to 43.41 points $(p<0.001)$ between $\mathrm{t}$ baseline and t $3 \mathrm{~m}$ and from 43.41 to 46.42 points $(p<0.001)$ between $\mathrm{t} \_3 \mathrm{~m}$ and $\mathrm{t} 6 \mathrm{~m}$.

\section{Factors associated with CRF during chemotherapy}

Multiple stepwise regression was used to analyze the predictors. The introduced independent variables included demographic variables (age, sex, education, marital status, employment status, and monthly household income), disease characteristic variables (diagnosis, overall stage of disease, colostomy, and type of chemotherapy), the three baseline subscale scores (physical fatigue, affective fatigue, and cognitive fatigue), and the baseline total fatigue score. Table 4 shows that baseline fatigue subscale score was the strongest predictor of each dimension of fatigue. In addition, age had an effect on physical fatigue, and monthly income and education had effects on cognitive fatigue.

\section{Discussion}

The first goal of this study was to analyze time-varying trends in colorectal cancer fatigue in chemotherapy patients. We assessed the prevalence of fatigue among colorectal cancer patients who underwent chemotherapy, at baseline and at 3 and 6 months of chemotherapy. The results showed that fatigue was at a moderate level at baseline, with an average score of 39.48 (out of 75), and that it gradually increased with the progression of chemotherapy and reached a moderate-tosevere level at 6 months (46.42/75). It is difficult to compare fatigue across studies due to differences in the criteria used to define fatigue, the measurement instruments used, the time points selected, and the treatment modalities. Most previous studies have shown similar results: cancer patients receiving adjuvant chemotherapy have higher levels of fatigue than the general population, and their fatigue lasts for many years than that of the general population [6, 19-24].

In the present study, there were statistically significant, sustained increases in the physical fatigue and total fatigue scores. The affective fatigue and cognitive fatigue scores increased significantly between baseline and 3 months and remained almost stable between 3 and 6 months. The results of this study are similar to those of Kecke et al., who followed 354 women with cancer for 3 months and assessed their fatigue. They found no significant change in affective fatigue but increases in physical and cognitive fatigue [25].

Van et al., in a study of long-term cancer survivors, found that chemotherapy was associated with higher levels of fatigue [26]. Increased fatigue during chemotherapy may be associated with anemia, leukopenia, sleep disturbances, and other symptoms during chemotherapy, such as pain, gastrointestinal reactions, and bone marrow suppression [27]. However, other studies have shown inconsistent results; for example, Servaes et al. conducted a longitudinal study of breast cancer survivors
Table 2 Levels of fatigue at baseline and follow-up $(n=174)$

\begin{tabular}{llllll}
\hline & $\begin{array}{l}\text { T_Baseline } \\
\text { M(SD) }\end{array}$ & $\begin{array}{l}\text { T_3 m } \\
\text { M(SD) }\end{array}$ & $\begin{array}{l}\text { T_6 m } \\
\text { M(SD) }\end{array}$ & $F$ & $P$ \\
\hline Physical fatigue & $18.05(3.06)$ & $20.32(2.84)$ & $23.16(3.56)$ & 171.37 & $<0.001$ \\
Affective fatigue & $10.85(2.63)$ & $12.02(2.56)$ & $12.01(2.59)$ & 20.72 & $<0.001$ \\
Cognitive fatigue & $10.58(2.49)$ & $11.07(2.39)$ & $11.25(2.96)$ & 4.57 & 0.01 \\
Fatigue total score & $39.48(6.48)$ & $43.41(5.69)$ & $46.42(6.63)$ & 90.58 & $<0.001$ \\
\hline
\end{tabular}

Abbreviations: $S D$ standard deviation 
a
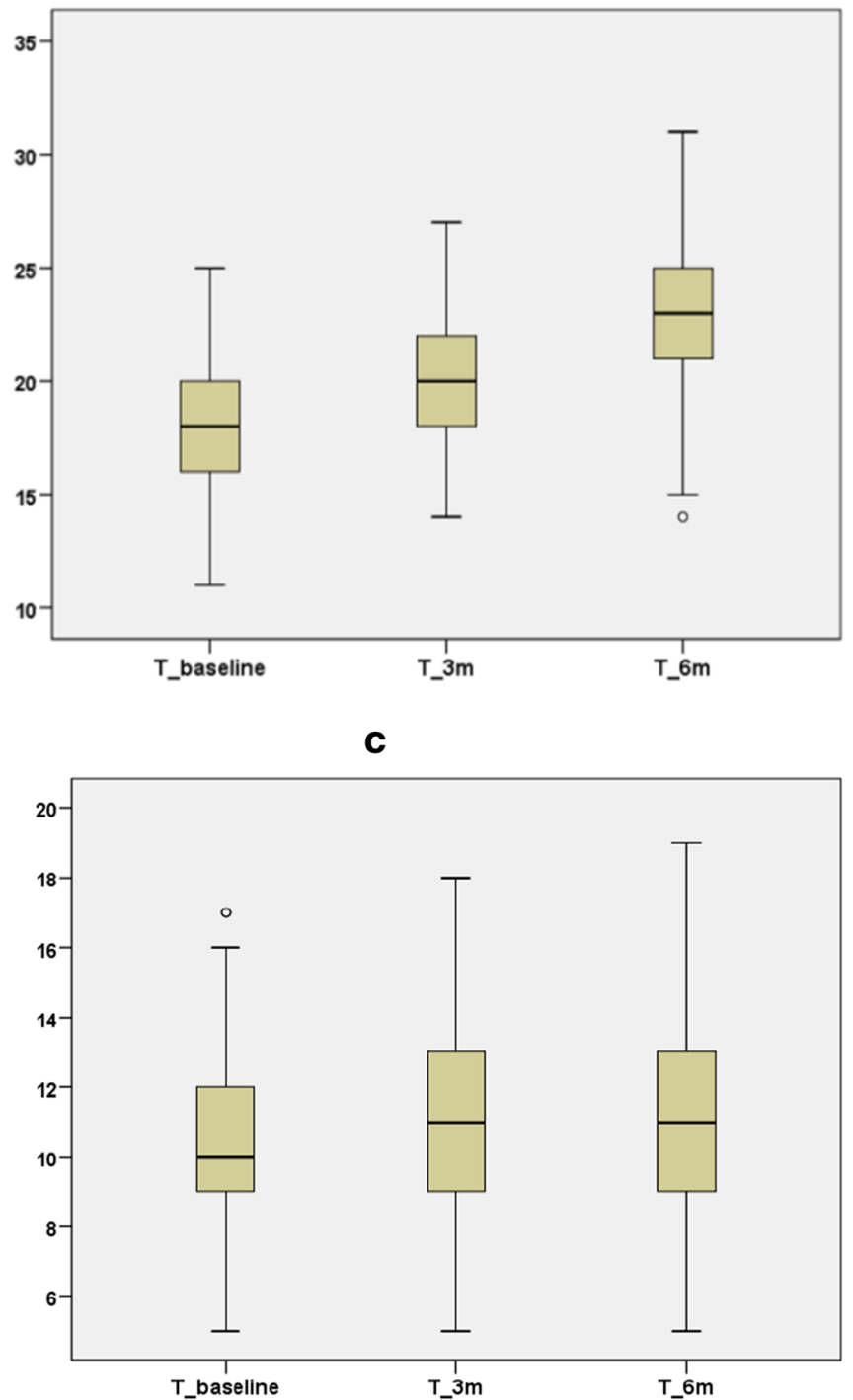

b

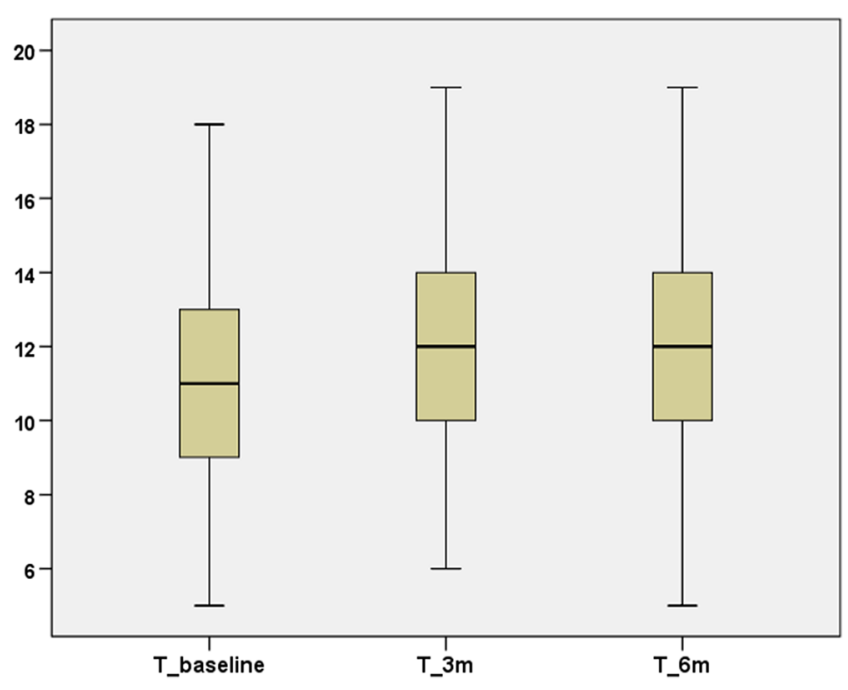

d

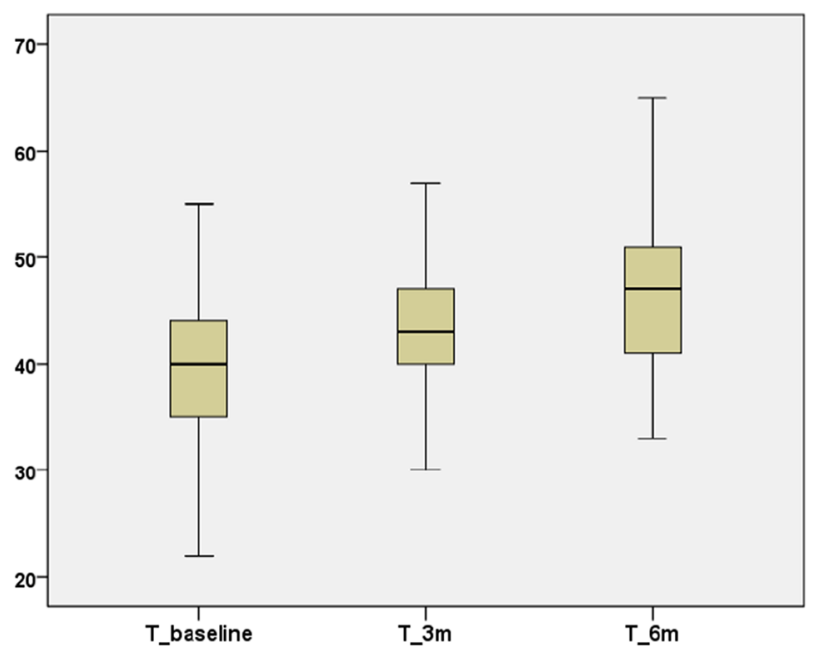

Fig. 1 Trajectory of cancer-related fatigue during chemotherapy. a Physical fatigue. b Affective fatigue. c Cognitive fatigue. $\mathbf{d}$ Total fatigue

and found no relationship between adjuvant therapy and fatigue [19]. In Muijen's study, fatigue was surprisingly negatively correlated with chemotherapy, with nearly $75 \%$ of respondents who received chemotherapy reporting lower fatigue than those who did not receive chemotherapy
[14]. In addition, Kuhnt Susanne found significant changes in fatigue in patients in a cancer rehabilitation program during 6 months of follow-up, and fatigue levels, particularly physical fatigue levels, were significantly lower than those at baseline [28]. These findings

Table 3 Differences in the subscale and total fatigue scores at all points of assessment $(n=174)$

\begin{tabular}{|c|c|c|c|c|c|c|c|c|c|}
\hline & \multicolumn{4}{|c|}{$\mathrm{T} \_3 \mathrm{~m}$ - $\mathrm{T}$ _baseline } & \multicolumn{4}{|c|}{$\mathrm{T} \_6 \mathrm{~m}-\mathrm{T} \_3 \mathrm{~m}$} & \multirow[t]{2}{*}{$\eta^{2}$} \\
\hline & Mean & SE & $p$ & $95 \% \mathrm{CI}$ & Mean & SE & $p$ & $95 \% \mathrm{CI}$ & \\
\hline Physical fatigue & 2.26 & 0.25 & $<0.001$ & $1.77-2.76$ & 2.84 & 0.27 & $<0.001$ & $2.31-3.38$ & 0.50 \\
\hline Affective fatigue & 1.17 & 0.20 & $<0.001$ & $0.78-1.56$ & -0.02 & 0.20 & 0.931 & -0.41 to 0.38 & 0.11 \\
\hline Cognitive fatigue & 0.49 & 0.21 & 0.021 & $0.07-0.90$ & 0.18 & 0.22 & 0.406 & -0.25 to 0.62 & 0.03 \\
\hline Total score & 3.93 & 0.48 & $<0.001$ & $2.99-4.87$ & 3.01 & 0.48 & $<0.001$ & $2.05-3.96$ & 0.34 \\
\hline
\end{tabular}

Abbreviations: SE standard error 
Table 4 Results of the multiple stepwise regression analysis of factors associated with cancer-related fatigue during chemotherapy among colorectal cancer patients $(n=174)$

\begin{tabular}{|c|c|c|c|c|c|c|c|c|c|}
\hline Dep. variables & Step & Indep. variables & $B$ & Beta & $p$ & $95 \% \mathrm{CI}$ & $R^{2}$ & Adj. $R^{2}$ & $P$ \\
\hline \multirow[t]{3}{*}{ Physical fatigue } & 1 & Physical (baseline) & 0.32 & 0.28 & $<.001$ & $(0.16,0.49)$ & 0.08 & 0.07 & $<.001$ \\
\hline & \multirow[t]{2}{*}{2} & Physical (baseline) & 0.35 & 0.30 & $<.001$ & $(0.18,0.51)$ & 0.12 & 0.11 & $<.001$ \\
\hline & & age & 0.07 & 0.20 & 0.007 & $(0.02,0.12)$ & & & \\
\hline Affective fatigue & 1 & Affective (baseline) & 0.33 & 0.33 & $<.001$ & $(0.19,0.47)$ & 0.11 & 0.11 & $<.001$ \\
\hline \multirow[t]{6}{*}{ Cognitive fatigue } & 1 & Cognitive (baseline) & 0.29 & 0.24 & 0.001 & $(0.11,0.46)$ & 0.06 & 0.05 & 0.001 \\
\hline & \multirow[t]{2}{*}{2} & Cognitive (baseline) & 0.31 & 0.26 & $<.001$ & $(0.14,0.49)$ & 0.10 & 0.09 & $<.001$ \\
\hline & & income & 0.80 & 0.21 & 0.005 & $(0.24,1.36)$ & & & \\
\hline & \multirow[t]{3}{*}{3} & Cognitive (baseline) & 0.33 & 0.28 & $<.001$ & $(0.16,0.50)$ & 0.13 & 0.11 & $<.001$ \\
\hline & & income & 0.74 & 0.19 & 0.009 & $(0.18,1.29)$ & & & \\
\hline & & Education & -0.76 & -0.17 & 0.018 & $(-1.38,-0.13)$ & & & \\
\hline \multirow[t]{3}{*}{ Total score } & 1 & Total (baseline) & 0.77 & 0.30 & $<.001$ & $(0.41,1.13)$ & 0.09 & 0.09 & $<.001$ \\
\hline & \multirow[t]{2}{*}{2} & Total (baseline) & 0.81 & 0.32 & $<.001$ & $(0.45,1.16)$ & 0.13 & 0.12 & $<.001$ \\
\hline & & Education & -1.82 & -0.19 & 0.01 & $(-3.21,-0.44)$ & & & \\
\hline
\end{tabular}

indicate that concurrent rehabilitation programs during chemotherapy may reduce fatigue.

Our second purpose was to examine the associations of the predictors with fatigue over a 6-month period. According to the results of the regression analyses, baseline fatigue was the strongest predictive factor of long-term fatigue during chemotherapy. Similar results have been reported in studies by Vardy et al., whose results indicated that the predictors of persistent fatigue are baseline fatigue, treatment, and emotional symptoms [6, 16, 29]. However, most of these studies followed the fatigue of cancer survivors, using fatigue at the end of acute treatment as a baseline for predicting long-term fatigue. Our study was a longitudinal study of fatigue during chemotherapy and used the fatigue score before chemotherapy as the baseline, which could better predict changes in fatigue during chemotherapy.

Although the proportion of variance explained by sociodemographic and clinical variables was small, the changes in the $R^{2}$ value were significant. Age appeared to have a significant impact on physical fatigue. The decline in function in older patients may be an important reason for their more severe fatigue than that of younger patients. In other studies, age has also been shown to be an important and related risk factor, with the effect of age on long-term fatigue increasing as the disease progresses [30-33]. Thus, it seems that we should pay more attention to the fatigue of elderly cancer patients.

This study also found that income and education predicted cognitive fatigue, but to a lesser level than did other sociodemographic and clinical variables. Previous studies have focused less on the effects of income and education on fatigue, possibly because these studies rarely performed multidimensional analyses of fatigue. Patients with lower incomes and education levels may be more worried about economic problems, leading to the aggravation of their cognitive fatigue. In Muijen's follow-up of cancer survivors, fatigue had a greater impact on the ability to work for lower-income cancer survivors [14]. This finding indicates that we should pay more attention to the fatigue of low-income cancer patients and consider reducing their financial burden through better health care plans. Meanwhile, in addition to being related to baseline fatigue, the total fatigue score was also related to education, which was also a predictor of cognitive fatigue. It seems that cognitive fatigue has a greater influence on the total fatigue score than the other two dimensions of fatigue, which needs to be confirmed by further research.

Although a baseline assessment was included in this study, other chronic conditions or other treatments may have an impact on patients' fatigue during chemotherapy. In addition, CRF may persist for some time after chemotherapy. However, we assessed fatigue only before chemotherapy and at 3 months and 6 months after the beginning of chemotherapy, which may not have fully explained the trends in fatigue.

\section{Clinical implications}

The results confirmed that baseline fatigue is an important predictor of fatigue during chemotherapy. There are different predictors of physical fatigue, emotional fatigue, and cognitive fatigue, so it is necessary to study the multiple dimensions of fatigue. Our results support the hypothesis that the 
evaluation of fatigue by caregivers as early as possible and early intervention for patients with higher baseline fatigue, older age, lower family income, and lower education may yield greater benefits for patients during chemotherapy.

Materials availability The authors had full control of all of the primary data and will allow the journal to review the data if requested to do so.

\section{Code availability N/A}

\section{Author contribution}

Conceptualization and methodology: $\mathrm{XX}, \mathrm{CZ}$

Data collection: $\mathrm{YC}, \mathrm{BH}$, and DX

Original draft preparation: $\mathrm{XX}, \mathrm{YC}$, and $\mathrm{BH}$

Review and editing: all of the authors

Approval of the final manuscript: all of the authors

Funding This study was supported by the Zhejiang Health Department of China (Ref No. 2014KYA114)

Data availability The authors had full control of all of the primary data and will allow the journal to review the data if requested to do so

\section{Declarations}

Ethics approval and consent to participate Approval was obtained from the ethics committee of Sir Run Run Shaw Hospital. Before data collection, all participants were informed of the purposes and potential benefits/ risks of the research. Participation was completely voluntary. Informed consent forms were signed after consent was obtained.

Consent for publication All authors approved the final manuscript and agreed to publish it.

Conflict of interest The authors declare no competing interests.

Open Access This article is licensed under a Creative Commons Attribution 4.0 International License, which permits use, sharing, adaptation, distribution and reproduction in any medium or format, as long as you give appropriate credit to the original author(s) and the source, provide a link to the Creative Commons licence, and indicate if changes were made. The images or other third party material in this article are included in the article's Creative Commons licence, unless indicated otherwise in a credit line to the material. If material is not included in the article's Creative Commons licence and your intended use is not permitted by statutory regulation or exceeds the permitted use, you will need to obtain permission directly from the copyright holder. To view a copy of this licence, visit http://creativecommons.org/licenses/by/4.0/.

\section{References}

1. NCCN Guidelines Version 1.2019 Panel Members. Cancer-related fatigue. Natl Compr Cancer Netw. https://www.nccn.org/ professionals/physician gls/pdf/fatigue.pdf

2. Wang XS, Zhao F, Fisch MJ, O'Mara AM, Cella D, Mendoza TR, Cleeland CS (2014) Prevalence and characteristics of moderate to severe fatigue: a multicenter study in cancer patients and survivors. Cancer 120:425-432. https://doi.org/10.1002/cncr.28434
3. Shi Q, Smith TG, Michonski JD, Stein KD, Kaw C, Cleeland CS (2011) Symptom burden in cancer survivors 1 year after diagnosis: a report from the American Cancer Society's studies of cancer survivors. Cancer 117:2779-2790. https://doi.org/10.1002/cncr. 26146

4. Nowe E, Stbel-Richter Y, Sender A, Leuteritz K, Friedrich M, Geue K (2017) Cancer-related fatigue in adolescents and young adults: a systematic review of the literature. Crit Rev Oncol Hematol 118: 63-69. https://doi.org/10.1016/j.critrevonc.2017.09.015

5. Abrahams HJG, Gielissen MFM, Schmits IC, Verhagen CAH, Rovers MM, Knoop H (2016) Risk factors, prevalence, and course of severe fatigue after breast cancer treatment: a meta-analysis involving 12327 breast cancer survivors. Ann Oncol 27:965-974. https://doi.org/10.1093/annonc/mdw099

6. Vardy JL, Dhillon HM, Pond GR, Renton C, Dodd A, Zhang H, Clarke SJ, Tannock IF (2016) Fatigue in people with localized colorectal cancer who do and do not receive chemotherapy: a longitudinal prospective study. Ann Oncol Off J Eur Soc Med Oncol 27(9):1761-1767. https://doi.org/10.1093/annonc/mdw252

7. Jones JM, Olson K, Catton P, Catton CN, Fleshner NE, Krzyzanowska MK, McCready DR, Wong RKS, Jiang H, Howell D (2016) Cancer-related fatigue and associated disability in post-treatment cancer survivors. J Cancer Surviv 10:51-61. https://doi.org/10.1007/s11764-015-0450-2

8. Kim YA, Yun YH, Chang YJ, Lee J, Kim MS, Lee H-S, Zo J, Kim J, Choi YS, Shim YM, Yoon SJ (2014) Employment status and work-related difficulties in lung cancer survivors compared with the general population. Ann Surg 259:569-575. https://doi.org/10. 1097/SLA.0b013e318291db9d

9. Islam T, Dahlui M, Majid HA, Nahar AM, Mohd Taib NA, Su TT (2014) Factors associated with return to work of breast cancer survivors: a systematic review. BMC Public Health 14(Suppl 3):S8. https://doi.org/10.1186/1471-2458-14-S3-S8

10. Bower, Julienne E (2014) Cancer-related fatigue - mechanisms, risk factors, and treatments. Nat Rev Clin Oncol 11(10):597-609. https://doi.org/10.1038/nrclinonc.2014.127

11. Lynn HG (2017) Cancer-related fatigue: persistent, pervasive, and problematic. Phys Med Rehabil Clin N Am 28(1):65-68. https:// doi.org/10.1016/j.pmr.2016.08.004

12. Tian L, Lin L, Li HL, Chen KJ, Zhang XJ, Qian SJ, Hu Y (2016) Prevalence and associated factors of cancer-related fatigue among cancer patients in eastern China. Oncologist:1349-1354. https:// doi.org/10.1634/theoncologist.2015-0537

13. Corbett T, Walsh JC, Groarke AM, Moss-Morris R, Mcguire BE (2017) Cancer-related fatigue in post-treatment cancer survivors: theory-based development of a web-based intervention. Jmir Cancer 3(2):e8. https://doi.org/10.2196/cancer.6987

14. van Muijen P, Duijts SFA, Bonefaas-Groenewoud K, van der Beek AJ, Anema JR (2017) Predictors of fatigue and work ability in cancer survivors. Occup Med (Lond) 67:703-711. https://doi.org/ 10.1093/occmed/kqx165

15. Fisch MJ, Zhao F, O'Mara AM, Wang XS, Cella D, Cleeland CS (2014) Predictors of significant worsening of patient-reported fatigue over a 1-month timeframe in ambulatory patients with common solid tumors. Cancer 120:442-450. https://doi.org/10.1002/ cncr.28437

16. Kreissl S, Mueller H, Goergen H, Mayer A, Brillant C, Behringer K, Halbsguth TV, Hitz F, Soekler M, Shonukan O, Rueffer JU, Flechtner HH, Fuchs M, Diehl V, Engert A, Borchmann P (2016) Cancer-related fatigue in patients with and survivors of Hodgkin's lymphoma: a longitudinal study of the German Hodgkin study group. Lancet Oncol 17:1453-1462. https://doi.org/10.1016/ S1470-2045(16)30093-6

17. Okuyama T, Akechi T, Kugaya A, Okamura H, Uchitomi Y (2000) Development and validation of the cancer fatigue scale. J Pain 
Symptom Manag 19(1):5-14. https://doi.org/10.1016/S08853924(99)00138-4

18. Feng-Ling Z, Yue D (2011) Reliability and validity of the Chinese version of cancer fatigue scale. Chin Ment Health J 25(11):810 813. https://doi.org/10.1631/jzus.B1000196

19. Servaes P, Gielissen MFM, Verhagen S, Bleijenberg G (2010) The course of severe fatigue in disease-free breast cancer patients: a longitudinal study. Psychooncology 16(9):787-795. https://doi. org/10.1002/pon. 1120

20. Goedendorp MM, Andrykowski MA, Donovan KA, Jim HS, Phillips KM, Small BJ, Laronga C, Jacobsen PB (2011) Prolonged impact of chemotherapy on fatigue in breast cancer survivors. Cancer 118:3833-3841. https://doi.org/10.1002/cncr.26226

21. Thong MSY, Mols F, Wang XS, Lemmens VEPP, Smilde TJ, Vand PLV (2013) Quantifying fatigue in (long-term) colorectal cancer survivors: a study from the population-based patient reported outcomes following initial treatment and long term evaluation of survivorship registry. Eur J Cancer 49(8):1957-1966. https://doi. org/10.1016/j.ejca.2013.01.012

22. Andrykowski MA, Donovan KA, Laronga C, Jacobsen PB (2010) Prevalence, predictors, and characteristics of off-treatment fatigue in breast cancer survivors. Cancer 116(24):5740-5748. https://doi. org/10.1002/cncr.25294

23. Bower JE, Ganz PA, Desmond KA, Bernaard C, Rowland JH, Meyerowitz BE (2010) Fatigue in long-term breast carcinoma survivors: a longitudinal investigation. Cancer 106(4):751-758. https://doi.org/10.1002/cncr.21671

24. Poort H, Rooij B, Uno H, Weng S, Ezendam N, Lonneke V, Wright A (2020) Patterns and predictors of cancer related fatigue in ovarian and endometrial cancers: 1-year longitudinal study. Cancer 126(15):3526-3533. https://doi.org/10.1002/cncr.32927

25. Kecke S, Ernst J, Einenkel J, Singer S, Hinz A (2017) Psychometric properties of the fatigue questionnaire EORTC QLQ-FA12 in a sample of female cancer patients. J Pain Symptom Manag 54: 922-928. https://doi.org/10.1016/j.jpainsymman.2017.08.007

26. Olga H, Mols F, Lemmens VEPP, de Vries J, Goof S, Thong MSY (2015) Variation in fatigue among 6011 (long-term) cancer survivors and a normative population: a study from the population-based profiles registry. Support Care Cancer 23(7):2165-2174. https:// doi.org/10.1007/s00520-014-2577-5

27. Denieffe S, Cowman S, Gooney M (2014) Symptoms, clusters and quality of life prior to surgery for breast cancer. J Clin Nurs 23(1718):2491. 2491-2502. https://doi.org/10.1111/jocn.12430

28. Susanne K, Michael F, Thomas S, Peter E, Andreas H (2019) Predictors of fatigue in cancer patients: a longitudinal study. Support Care Cancer 27(9):3463-3471. https://doi.org/10.1007/ s00520-019-4660-4

29. Peoples AR, Roscoe JA, Block RC, Heckler CE, Ryan JL, Mustian KM, Janelsins MC, Peppone LJ, Moore DF, Coles C, Hoelzer KL, Morrow GR, Dozier AM (2017) Nausea and disturbed sleep as predictors of cancer-related fatigue in breast cancer patients: a multicenter NCORP study. Support Care Cancer 25:1271-1278. https://doi.org/10.1007/s00520-016-3520-8

30. Heutte N, Flechtner HH, Mounier N, Mellink WA, Meerwaldt JH, Eghbali H, van't Veer MB, Noordijk EM, Kluin-Nelemans JC, Lampka E et al (2009) EORTC-GELA H8 Trial Group. Quality of life after successful treatment of early-stage Hodgkin's lymphoma: 10-year follow-up of the EORTC-GELA H8 randomised controlled trial. Lancet Oncol 10:1160-1170. https://doi.org/10.1016/ S1470-2045(09)70258-X

31. Ruffer JU, Flechtner H, Tralls P, Josting A, Diehl V (2003) Fatigue in long-term survivors of Hodgkin's lymphoma; a report from the German Hodgkin Lymphoma Study Group (GHSG). Eur J Cancer 39:2179-2186. https://doi.org/10.1016/S0959-8049(03)00545-8

32. Hjermstad MJ, Fossa SD, Oldervoll L, Holte H, Jacobsen AB, Loge JH (2005) Fatigue in long-term Hodgkin's disease survivors: a follow-up study. J Clin Oncol 23:6587-6595. https://doi.org/10. 1200/JCO.2005.09.936

33. Young KE, White CA (2006) The prevalence and moderators of fatigue in people who have been successfully treated for cancer. $\mathrm{J}$ Psychosom Res 60(1):29-38. https://doi.org/10.1016/j.jpsychores. 2005.03.011

Publisher's note Springer Nature remains neutral with regard to jurisdictional claims in published maps and institutional affiliations. 